\title{
QUESTIONNAIRE TO ASSESS A TEACHER'S PERCEPTION OF THEIR CURRENT PERSONAL COMMITMENT AND PREFERRED FUTURE COMMITMENT TO EACH OF THE EIGHT ROLES: TURKISH VERSION
}

\author{
Bennur Koca ${ }^{1}$, Esin Ergonul ${ }^{2}$, Murat Bektas ${ }^{3}$, Funda Ifakat Tengız ${ }^{4}$, Erol \\ Gurpinar ${ }^{5}$, Sebahat Gozum ${ }^{6}$
}

\footnotetext{
${ }^{1}$ Dr. Lecturer, PhD, RN, Vocational School of Health Services, First and Emergency Aid Program, Dokuz Eylul University, Izmir, Turkey

${ }^{2}$ Assoc.Prof. Dr. PhD, MD Vocational School of Health Services, Medical Documentation and Secretariat, Dokuz Eylul University, Izmir, Turkey

${ }^{3}$ Prof.Dr. PhD, RN, Faculty of Nursing, Department of Pediatric Nursing, Dokuz Eylul University, Izmir, Turkey,

${ }^{4}$ Asst. Prof.Dr. PhD, MD, Faculty of Medicine, Department of Medical Education, Katip Celebi University, Izmir, Turkey

${ }^{5}$ Prof.Dr. MD, PhD, Faculty of Medicine, Department of Medical Education, Akdeniz University, Antalya, Turkey,

${ }^{6}$ Prof.Dr. PhD, RN, Faculty of Nursing, Department of Public Health Nursing, Akdeniz University, Antalya, Turkey,
}

Address for Correspondence: Bennur Koca E-mail: kocabennur78@gmail.com

Received: 19.04.2021; Accepted: 27.05.2021; Available Online Date: 27.05.2021

CCopyright 2021 by Dokuz Eylül University, Institute of Health Sciences - Available online at https://dergipark.org.tr/en/pub/jbachs

Cite this article as: Koca B, Ergonul E, Bektas M, Ifakat-Tengiz F, Gurpinar E, Gozum S. Questıonnaıre To Assess A Teacher's Perception Of Theır Current Personal Commıtment And Preferred Future Commıtment To Each Of The Eıght Roles: Turkısh Versıon J Basic Clin Health Sci 2021; 2: 162-171.

\section{ABSTRACT}

Introduction: There are eight key roles defined for trainers. The trainer is expected to identify their roles in a training program and maximize their potential. This study aimed to expand the "Questionnaire to Assess a Teacher's Perception of Their Current Personal Commitment and Preferred Future Commitment to Each of the Eight Roles", which was developed by Harden and Lilley 2018, and adapt it to Turkish.

Method: The study was carried out in four faculties between 10 December 2018 and 30 August 2019. The original questionnaire, which questioned the roles of an educator over a total of eight items, was expanded in accordance with the source in which it was published. The psychometric analyses of the new scale consisting of 32 items were conducted.

Results: The final version of the scale consisted of 29 items and eight subscales. The scale-based content validity index for the scale was calculated as 1.00 . Cronbach's alpha values for the Scale and its subscales were $0.95,0.67,0.90,0.92,0.87,0.84,0.88,0.90$, and 0.78 , respectively. The item-total correlations for the scale and the Goodness of Fit model were deemed acceptable.

Conclusion: The scale proved useful as a measurement tool for measuring educators' current and future commitments to their eight roles. We recommend the scale for educator evaluation, needs assessment, and/or educator development training.

Keywords: Health educators, education, medical, role, nursing, reliability and validity 


\section{INTRODUCTION}

Ten years ago, Harden and Crosby emphasized in their AMEE Guide No 20 that teaching was a complex task, and they defined a total of 11 roles in 6 areas for educators (The information provider; the role model; the facilitator; the assessor and evaluator; the planner; and the creator and producer) (1).

Also, they stated that the model that they presented about the roles of educators was open to constant change and development. Time did not deny the authors in this respect, and with the practices in the medical field, the knowledge and experience of teaching and learning changed in line with the spirit of the time. Today, information and experiences on health education are shared from all over the world through hundreds of studies published every day. Educators and students can conduct literature review from anywhere; the information is compiled and presented to them by the associations they belong to; they are even provided with news by the journals as soon as information is shared $(2,3)$. Moreover, all of these can be accessed through smartphone applications and even via social media (4-8). New technologies such as virtual reality and $3 D(9,10)$ have introduced new perspectives, approaches, and applications to health education including interprofessional practices for patient well-being (11-13), monitoring of corporate development within national and international criteria (14-17), and increased use of social media in medicine and education (18-20). These changes have also necessitated changes in the roles of health educators. Therefore, ten years after the educational roles had been published, they were re-addressed by Harden and Lilley and redefined (Fig. 1) (8). In their new work, the authors presented an eight-item questionnaire that let

Table 1 Mean rating by 251 educators as to the relative importance of the eight roles of the teacher

\begin{tabular}{|c|c|c|c|}
\hline Teacher's role & $\begin{array}{l}\text { Current } \\
\text { Mean rating }\end{array}$ & $\begin{array}{l}\text { Future } \\
\text { Mean rating }\end{array}$ & p value* \\
\hline 1. Information provider and coach & 8.61 & 8.43 & 0.063 \\
\hline (1.1) Conduit for information-transmitting information to the student & 4.31 & 4.18 & \\
\hline (1.2) Curator of information filtering and making information available & 4.30 & 4.25 & \\
\hline 2. Facilitator and mentor & 20.89 & 22.48 & $<0.001$ \\
\hline $\begin{array}{l}\text { (1.3) Information coach- guiding student to ask the right question, source } \\
\text { information and evaluate information received }\end{array}$ & 4.31 & 4.59 & \\
\hline (2.1) Clarifying learning outcomes & 4.17 & 4.46 & \\
\hline (2.2) Identifying appropriate learning opportunities & 4.05 & 4.41 & \\
\hline (2.3) Making learning effective and efficient & 4.18 & 4.53 & \\
\hline (2.4) Engaging and motivating the student serving as a mentor & 4.18 & 4.49 & \\
\hline 3. Assessor and diagnostician & 18.38 & 21.04 & $<0.001$ \\
\hline (3.2) Plan and implement assessment of for your course learners & 3.87 & 4.22 & \\
\hline (3.3) Monitor students' performance and progress & 3.65 & 4.23 & \\
\hline (3.4) Decide about learners' performance and progress & 3.62 & 4.09 & \\
\hline (3.5) Provide feedback to students & 3.71 & 4.32 & \\
\hline (3.6) Evaluate and change the assessment where necessary & 3.53 & 4.18 & \\
\hline 4. Curriculum developer and implementer & 15.92 & 17.54 & $<0.001$ \\
\hline (3.1) Be familiar with the school's approach to assessment & 3.91 & 4.28 & \\
\hline (4.1) Be familiar with the school's curriculum & 4.03 & 4.43 & \\
\hline $\begin{array}{l}\text { (4.2) Plan and implement your own course in line with the school's } \\
\text { curriculum }\end{array}$ & 4.18 & 4.51 & \\
\hline (4.3) Evaluate the curriculum and plan for changes & 3.80 & 4.32 & \\
\hline
\end{tabular}


Table 1 in contuniation

$\begin{array}{lcc}\text { 5. Role model as a teacher and practitioner } & \mathbf{1 0 . 3 6} & \mathbf{1 1 . 7 9} \mathbf{0 . 0 0 1} 3.57 \\ \begin{array}{l}\text { (5.1) Influences students' lifestyle choices } \\ \text { (5.2) Influences students' career choices }\end{array} & 3.07 & 3.39 \\ \text { (5.5) Contributes to a learning environment that supports students' learning } & 3.90 & 4.37\end{array}$

\begin{tabular}{|c|c|c|c|}
\hline 6. Manager and leader & 10.36 & 11.79 & $<0.001$ \\
\hline (6.1) Engaging with the decision-making process & 3.58 & 4.14 & \\
\hline (6.2) Managing elements in the curriculum & 3.60 & 4.13 & \\
\hline (6.3) Supporting change and overcoming obstacles & 3.68 & 4.17 & \\
\hline 7. Scholar and researcher & 16.57 & 18.50 & $<0.001$ \\
\hline (7.1) Identifying what works and what does not work & 4.09 & 4.58 & \\
\hline (7.2) Applying evidence to practice & 4.15 & 4.62 & \\
\hline (7.3) Research and innovation & 4.06 & 4.62 & \\
\hline (7.4) Sharing your experiences with others & 4.27 & 4.68 & \\
\hline 8. Professional & 12.48 & 13.94 & $<0.001$ \\
\hline (8.2) Acquisition of necessary competencies and keeping up to date & 4.40 & 4.72 & \\
\hline (8.3) Supporting personal well-being & 3.88 & 4.61 & \\
\hline (8.4) "Civic" professionalism & 4.20 & 4.61 & \\
\hline
\end{tabular}

*Pared sample t-test for each role's total scores

educators define their relationships with their roles for the current and future. We believe that the scale will not only direct the educators but also guide the institutions in determining their own educator needs, evaluating educators, and planning educator development training. For this reason, we aimed to expand the "Questionnaire to Assess a Teacher's Perception of $\mathrm{His}$ or Her Current Personal Commitment and Preferred Future Commitment to Each of the Eight Roles", which is found in Harden and Lilley's book of the Eight Roles of the Medical Teacher (2018) and adapt it to Turkish in accordance with the book by doing its psychometric analyses. Consequently, we aimed to provide the scale in the Turkish language.

\section{METHODS}

\section{Participants}

The study was carried out in four faculties including two medical faculties and two nursing faculties in Turkey between 10 December 2018 and 30 August 2019. There were 541 faculty members in four faculties. In the literature, recruiting at least 10 subjects per item is recommended when determining the number of samples in scale development or adaptation studies (21-23). For this reason, the sample size was calculated as 310 subjects. We aimed to reach to all of 541 educators in four schools.

\section{Instrument Development}

The original questionnaire measures the current personal commitments and preferred future commitments of educators regarding the eight roles (8). It consists of eight subscales both for current and for the future: including (1) information provider and coach, (2) facilitator and mentor, (3) assessor and diagnostician, (4) curriculum developer and implementer, (5) role model as a teacher and practitioner, (6) manager and leader, (7) scholar and researcher, and (8) professional. Each item is scored on a Likert scale (1 none; 2 little; 3 some; 4 considerable; 5 great). As for the interpretation of the scores, the higher the score obtained for each role, 
Table 2 Eigenvalue and Factor Loads According to Exploratory Factor Analysis $(n=282)$

\begin{tabular}{l} 
Subscales / Items \\
\hline 1. Information provider and coach \\
(1.1) Conduit for information-transmitting information to the student \\
(1.2) Curator of information filtering and making information available \\
2. Facilitator and mentor \\
(1.3) Information coach- guiding student to ask the right question, source information and \\
evaluate information received \\
(2.1) Clarifying learning outcomes \\
(2.2) Identifying appropriate learning opportunities \\
(2.3) Making learning effective and efficient \\
(2.4) Engaging and motivating the student serving as a mentor
\end{tabular}

\begin{tabular}{ll} 
Eigenvalues & $\begin{array}{l}\text { Factor } \\
\text { loads }\end{array}$ \\
\hline 4.279 & \\
& 0.842 \\
& 0.663
\end{tabular}

3.755

3. Assessor and diagnostician

3.438

(3.2) Plan and implement assessment of for your course learners

(3.3) Monitor students' performance and progress

(3.4) Decide about learners' performance and progress

(3.5) Provide feedback to students

(3.6) Evaluate and change the assessment where necessary

4. Curriculum developer and implementer

(3.1) Be familiar with the school's approach to assessment

(4.1) Be familiar with the school's curriculum

(4.2) Plan and implement your own course in line with the school's curriculum

the higher the commitment of the educator to the relevant role.

Harden and Lilley's original questionnaire consisted of a total of eight items mentioned above. This source containing the questionnaire, presented detailed explanations and diagrams for each role. We added sub-questions to each role in line with these diagrams. These sub-questions were, in fact, expressions which were already placed in the diagrams by Harden and Lilley in the original language of the source. We put these statements in the table exactly as they were without changing them. Thus, we obtained a scale of 32 items in total. We shared this new scale with Harden RM, and then we carried out the validity and reliability analysis after the approval of the author. For analysis, we followed the following steps suggested by WHO: Forward translation; expert panel; back-translation; pre-testing and cognitive interviewing; and final version (24).

\section{Content Validity}

The scale was translated into Turkish by three different experts. The translated version was finalized by the researchers. Then it was submitted to the views of two field experts. The experts were given the original and the translated form of the scale and were asked to rate the appropriateness of the questionnaire items from 1 to 4 . Also, their written recommendations were received accordingly.

\section{Pilot Study}

The scale was piloted to 30 volunteer educators, who were not included in the sample, in March 2019, and feedback evaluations were done. 
Table 2 in contuniation

\begin{tabular}{|c|c|c|}
\hline Subscales / Items & Eigenvalues & $\begin{array}{l}\text { Factor } \\
\text { loads }\end{array}$ \\
\hline 5. Role model as a teacher and practitioner & 2.464 & \\
\hline (5.1) Influences students' lifestyle choices & & 0.857 \\
\hline (5.2) Influences students' career choices & & 0.806 \\
\hline
\end{tabular}

6. Manager and leader

2.252

(6.1) Engaging with the decision-making process

(6.2) Managing elements in the curriculum

(6.3) Supporting change and overcoming obstacles

7. Scholar and researcher

1.853

(7.1) Identifying what works and what does not work

(7.2) Applying evidence to practice

(7.3) Research and innovation

(7.4) Sharing your experiences with others

8. Professional

1.485

(8.2) Acquisition of necessary competencies and keeping up to date

0.720

(8.3) Supporting personal well-being

0.799

(8.4) "Civic" professionalism
0.708

0.724

0.760

0.725

0.786

0.705

0.793

\section{Pilot Study}

The scale was piloted to 30 volunteer educators, who were not included in the sample, in March 2019, and feedback evaluations were done.

Data collection forms were handed out to the educators by the researchers by visiting each educator's office and explaining the purpose of the study. The forms were collected after the researchers filled them out. The data form involved "The Questionnaire to Assess a Teacher's Perception of

His or Her Current Personal Commitment and Preferred Future Commitment to Each of the Eight Roles" collecting socio-demographic information about the educators (gender, age, specialty, department, number of educators in the department, working years, the status of participating in educator training) and their perception regarding the roles. Of the 541 trainers in four schools, 282 were reached. The response rate was found to be $52 \%$.

\section{Data Analysis}

Descriptive data were analyzed with numbers, percentages, and mean scores. IBM SPSS Statics 24 software package was used for validity and reliability analyses, and LISREL was utilized for confirmatory factor analysis (CFA). Item-level content validity index $(\mathrm{I}-\mathrm{CVI})$ and scale-level content validity index (S-CVI) were used for evaluating the content validity. Exploratory factor analysis (EFA) and CFA were employed for construct validity. In the EFA, eigenvalue was taken 1 and greater, and principal components analysis and varimax rotation technique were employed to determine under which factors the items would be grouped. The fit of the construct formed as a result of EFA was analyzed through CFA. The internal consistency was calculated using Cronbach's alpha coefficient and split-half technique. Item total score and item subscale total score analyses were employed to determine the fit of the items with the overall scale. 
Table 3 Reliability Analysis Results of the Scale ( $n=282)$

\begin{tabular}{|c|c|c|c|c|c|c|c|c|}
\hline & $\begin{array}{c}\text { Total } \\
\text { Cronbach } \\
\text { Alfa }\end{array}$ & $\begin{array}{c}\text { First Half } \\
\text { Cronba } \\
\text { ch } \\
\text { Alfa }\end{array}$ & $\begin{array}{c}\text { Second } \\
\text { Half } \\
\text { Cronba } \\
\text { ch } \\
\text { Alfa }\end{array}$ & Spearman-Brown & $\begin{array}{c}\text { Guttman } \\
\text { split- } \\
\text { half }\end{array}$ & $\begin{array}{c}\text { Correlation } \\
\text { between } \\
\text { two halves }\end{array}$ & Mean & SD \\
\hline Total Score of the Scale & 0.95 & 0.906 & 0.922 & 0.913 & 0.910 & 0.839 & 114.20 & 17.76 \\
\hline 1. Information provider and coach & 0.67 & & & & & & 8.61 & 1.24 \\
\hline 2. Facilitator and mentor & 0.90 & & & & & & 20.88 & 3.56 \\
\hline 3. Assessor and diagnostician & 0.92 & & & & & & 18.40 & 4.73 \\
\hline 4. Curriculum developer and implementer & 0.87 & & & & & & 15.92 & 3.21 \\
\hline 5. Role model as a teacher and practitioner & 0.84 & & & & & & 6.46 & 2.05 \\
\hline 6. Manager and leader & 0.88 & & & & & & 14.75 & 3.61 \\
\hline 7. Scholar and researcher & 0.90 & & & & & & 16.57 & 2.98 \\
\hline 8. Professional & 0.78 & & & & & & 12.49 & 2.02 \\
\hline
\end{tabular}

\section{Ethical approval}

We aimed to expand the "Questionnaire to Assess a Teacher's Perception of His or Her Current Personal Commitment and Preferred Future Commitment to Each of the Eight Roles", which is found in Harden and Lilley's book of the Eight Roles of the Medical Teacher (2018) and adapt it to Turkish in accordance with the book by doing its psychometric analyses. The permission of the authors of the original questionnaire (included eight items) was obtained by e-mail in September 2018. Later, in October 2018, it was reapproved by e-mail from Harden RM for its extended Table 4 Item Total-Test Correlations of Eight Sub-

Dimensions of the Scale

$$
{ }^{*} p<0.01 \text { significance level }
$$

version to 29 items. Also, the approval of the University Non-Interventional Research Ethics Committee (IRB approval number: 2019/03-35) and the written consent of the participants were obtained.

\section{RESULTS}

Of the educators participating in the study, $57 \%$ were female, the mean age was $46.54( \pm 7.71), 76 \%$ were working in the faculty of medicine, $24 \%$ were working in the faculty of nursing, and $86 \%$ were found to participate in educator training. When the scores given by the educators to their current and future commitment were compared, the future commitment scores were significantly lower for "information provider and coach" roles, while the scores were higher for the rest of the roles (Table 1) $(p<0.05)$.
Table 4. Item Total-Test Correlations of Eight SubDimensions of the Scale

\begin{tabular}{|c|c|}
\hline Number of items & $\begin{array}{l}\text { In Total-Test } \\
\text { Correlations }\end{array}$ \\
\hline IPC1 & $0.44^{*}$ \\
\hline IPC2 & $0.49^{*}$ \\
\hline IPC3 & $0.59^{*}$ \\
\hline FM1 & $0.66^{*}$ \\
\hline FM2 & $0.68^{*}$ \\
\hline FM3 & $0.69^{*}$ \\
\hline FM4 & $0.65^{\star}$ \\
\hline AD2 & $0.71^{*}$ \\
\hline AD3 & $0.75^{*}$ \\
\hline AD4 & $0.72^{*}$ \\
\hline AD5 & $0.74^{*}$ \\
\hline AD6 & $0.71^{*}$ \\
\hline AD1 & $0.66^{*}$ \\
\hline CDI1 & $0.70^{*}$ \\
\hline CDI2 & $0.64^{*}$ \\
\hline CDI3 & $0.69^{*}$ \\
\hline RM1 & $0.55^{*}$ \\
\hline RM2 & $0.62^{*}$ \\
\hline RM5 & $0.72^{*}$ \\
\hline ML1 & $0.68^{*}$ \\
\hline ML2 & $0.76^{*}$ \\
\hline ML3 & $0.72^{*}$ \\
\hline SR1 & $0.72^{*}$ \\
\hline SR2 & $0.65^{\star}$ \\
\hline SR3 & $0.69^{\star}$ \\
\hline SR4 & $0.63^{*}$ \\
\hline P2 & $0.49^{*}$ \\
\hline P3 & $0.48^{*}$ \\
\hline P4 & $0.56^{\star}$ \\
\hline
\end{tabular}




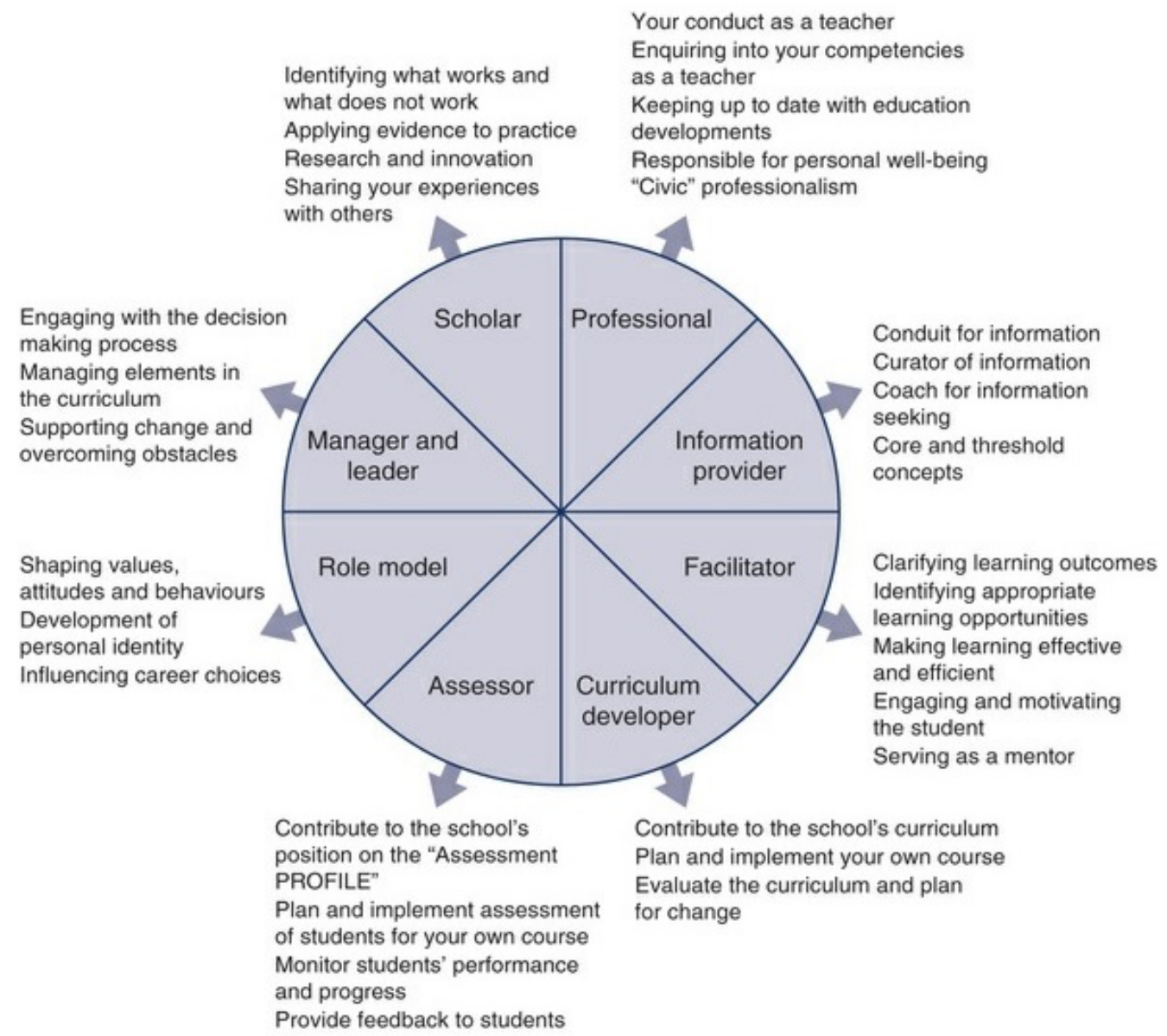

Fig. 1 The eight roles of the teacher (Harden and Lilley, 2018)

\section{Content Validity}

The scale-level CVI value of the newly developed 32item questionnaire was calculated as 1.00 .

\section{Construct Validity}

Prior to factor analysis, the Kaiser-Meyer-Olkin (KMO) value was found as 0.92 and the Barlett test was calculated as $x^{2}=5913.793, p<0.001$ for analyzing the suitability of the sample size. The EFA analysis done using the principal components analysis showed that the scale had eight factors whose eigenvalues were over 1.0. The percentages showing how much of the total variance the subscales explained were as follows: the first subscale, $15 \%$; the second subscale, $13 \%$; the third subscale, $12 \%$; the fourth subscale, $9 \%$; the fifth subscale, $9 \%$; the sixth subscale, $8 \%$; the seventh subscale, $6 \%$; and the eighth subscale, $5 \%$. The eight subscales explained $77 \%$ of the total variance. Table 2 shows the item-factor loadings $(\geq 0.30)$.
According to the results of the factor analysis, the third item (asking the student the right questions, guiding the students to use the information sources and to evaluate the information they acquired), which had previously been under the "information provider and coach" subscale was transferred to the "facilitator and mentor" subscale. Also, the first item (having information about school's approaches to evaluation), which had been under the "assessor and diagnostician" subscale previously, was moved to "curriculum developer and implementer" subscale. CFA was performed using the 29 items from the EFA (Fig. 2). The goodness of fit model was deemed acceptable (Chi-square $\mathrm{min} / \mathrm{df}=1.93$; RMSEA = 0.058 ; $\mathrm{GFI}=0.86 ; \mathrm{TLI}=0.98 ; \mathrm{CFI}=0.86$ and $\mathrm{NFI}=$ $0.97(24)$.

\section{Reliability Analysis}

As a result of the reliability analyses for the eight subscales of the scale, Cronbach's alpha coefficient 
was determined as 0.95 . The Cronbach's alpha value of the first half was found as 0.91 , and it was 0.92 for the second half. The spearman-brown coefficient was 0.913, the Guttman-Split-Half coefficient was 0.910 , and the correlation coefficient between the two halves was determined as 0.839 . The mean score of the scale was $114.20( \pm 17.76)$. Cronbach's alfa coefficients for the eight subscales are presented in Table 3.

Item-total score correlation coefficients are shown in Table 4. Item 3 (demonstrating the competence expected from a health worker), item 4 (helping students to acquire professional behavior), item 5 (contributing to the creation of a learning environment that supports students' learning) under "Role model as a teacher and practitioner" the subscale and item 1 (exhibiting sensible behaviors and fulfilling professional responsibilities) under "Professional" subscale were omitted from the scale since their total test correlations were below acceptable values. As a result of the removed items, the scale was determined to consist of eight subscales and a total of 29 items.

\section{DISCUSSION}

The S-CVI value should be greater than 0.80 to claim that there is an agreement between expert opinions. In this study, S-CVI values were found to be greater than 0.80. KMO and Barlett test values indicated that the sample size and data structure was suitable for factor analysis. In the exploratory factor analysis, the eigenvalue was accepted as 1 and above in determining the number of factors (27). Accordingly, eight factors with eigenvalues above 1 were determined in this study. The total explained variance by the eight factors was greater than $60 \%$, which indicated that the scale had a high level of explained variance. The high level of explained variance showed that the scale and the items were able to measure the desired phenomenon adequately and accurately. These results supported the appropriateness of the construct validity for the eight subscales of the scale, which assesses the eight roles of an educator.

In the literature, it is emphasized that when factor groups of the items are being determined, the minimum factor loadings of the items should be 0.30 or above, and the items below this value should be omitted from the scale $(24,26)$. In this study, item 3 (demonstrating the competence expected from a health worker), item 4 (helping students to acquire professional behavior), item 5 (contributing to the creation of a learning environment that supports students' learning) under "Role model as a teacher and practitioner" the subscale and item 1 (exhibiting sensible behaviors and fulfilling professional responsibilities) under "Professional" subscale were omitted from the scale because their total test correlations were below acceptable values. Three items were omitted from the scale because their factor loadings were less than 0.30 . Thus, the final form of the scale, which initially consisted of a total of 32 items, involved a total of 29 items with eight subdimensions.

As a result of the re-implemented CFA of the 29-item scale, the factor loadings in all subscales were determined to be greater than 0.30 . Also, the fit indices (GFI, NFI, CFI, and IFI) were found to be greater than 0.90 and RMSEA was less than 0.080 . The division of chi-square value by the degree of freedom was found to be less than five. In the literature, model fit indices greater than 0.90, an $X 2 / D F$ value less than five, and an RMSEA value less than 0.08 are considered to be a good fit indicator $(28$, 29). CFA results in this study were found to be consistent with the criteria specified in the literature. CFA results showed that the data were appropriate for the model, the eight-factor structure was confirmed, the subscales were relevant to the scale, and that the items in each sub-dimension explained their factor adequately. The CFA results in this study could not be compared to those of the original questionnaire because the analysis was not performed in the original questionnaire (8).

In the literature, Cronbach's alpha coefficient is calculated as an indicator of reliability. When this value is between 0.60 and 0.80 , the scale is accepted as very reliable, while a value between 0.80 and 1.00 shows that the scale is highly reliable. The split-half method is one of the recommended techniques for reliability analysis $(22,30)$. In this study, the total Cronbach's alpha, spearman-brown, and Guttman split-half values of the scale showed that the scale was highly reliable. These results showed that the items were related to each other and the subject to be measured, they measured the same structure and that they could do the measurement without errors unless the subjects of the study changed.

Item-total score analysis explains the relationship between the scores obtained from the scale items and the total score of the scale. This value should be positive and greater than $0.20(24,26)$. Both item-total 
score and item-subscale total score correlation coefficients of the total 29 items were found to be positive and greater than 0.20 . These results showed that each subscale of the 29 items in the scale was highly correlated with its total score, they adequately measured the intended quality, and that the item reliability of the overall scale and subscales were high. In the literature, no validity and reliability study of the questionnaire in another language other than the original language of the questionnaire was found; therefore, there was no possibility to discuss similar situations.

The participants were found to give lower scores to "information provider and coach" role regarding their current and future commitment to their roles. This suggested that the participants wanted to highlight other roles rather than information providing.

\section{Study Limitations}

The response rate of the study was $52 \%$. Although an acceptable number was reached, it was a limitation in terms of representativeness. Besides, the memory factor may have had a negative effect as the study was conducted only on a questionnaire basis.

\section{CONCLUSION}

In conclusion, the Turkish version of "the Questionnaire to Assess a Teacher's Perception of Their Current Personal Commitment and Preferred Future Commitment to Each of the Eight Roles" was determined to have a high level of reliability and validity. The scale can help educators to do a selfevaluation and to plan their professional development. We also think that the scale can be considered as a guiding instrument for identifying the educator needs of institutions, evaluating the trainers, and even determining the needs for educator training programs.

\section{Acknowledgments}

The present study was undertaken without external funding. We would like to extend our sincere thanks to Harden and Lilley, the developers of the "Questionnaire to Assess a Teacher's Perception of Their Current Personal Commitment and Preferred Future Commitment to Each of the Eight Roles", for giving us the permission to use the questionnaire.

Conflict of Interest: The authors declare no competing financial interests and no sources of funding and support, including any for equipment and medications.

Peer-review: Externally peer-reviewed.
}

\section{REFERENCES}

1. Harden RM, Crosby J. AMEE Guide No 20: The good teacher is more than a lecturer-the twelve roles of the teacher. Med Teach. 2000; 22(4):334347.

2. Harden RM. Ten key features of the future medical school-not an impossible dream. Med Teach.2018;40(10):1010-1015.

3. MedEdWord: e global medical education community. [Accessed 2019 Sep 9]. The [data are available https://www.mededworld.org/Resources/Publicati ons/Articles.aspx

4. Ravindran R, Kashyap M, Lilis L, Vivekanantham S, Phoenix G. Evaluation of an online medical teaching forum. Clin Teach.2014;11: 274-8.

5. Choo EK, Ranney ML, Chan TM, Trueger NS, Walsh AE, Tegtmeyer $\mathrm{K}$ et al. Twitter as a tool for communication and knowledge exchange in academic medicine: A guide for skeptics and novices. Med Teach.2015;37(5):411-416.

6. Gallardo-Echenique EE, de Oliveira JM, MarquesMolias L, esteve-Mon F. Digital competence in the knowledge society. MERLOT Journal of Online Learning and Teaching. 2015;11(1):1-16.

7. Purdy E, Thoma B, Bednarczyk J, Migneault D, Sherbino J. The use of free online educational resources by Canadian emergency medicine residents and program directors. CJEM. 2015;17(2):101-106.

8. Harden RM, Lilley P. The Eight Roles of the Medical Teacher: The Purpose and Function of a Teacher in the Healthcare Professions. The Eight Roles of the Medical Teacher.1st Edition. Elsevier,2018.

9. Lim KH, Loo ZY, Goldie SJ, Adams JW, McMenamin PG. Use of 3D printed models in medical education: $A$ randomized control trial comparing 3D prints versus cadaveric materials for learning external cardiac anatomy. Anat Sci Educ.2016;9(3):213-21.

10. AIAli AB, Griffin MF, Calonge WM, Butler PE. Evaluating the Use of Cleft Lip and Palate 3DPrinted Models as a Teaching Aid. J Surg Educ.2018; 75(1):200-208.

11. Reeves S, Macmillan K, van Soeren $M$. Leadership of interprofessional health and social care teams: a socio-historical analysis. J Nurs Manag.2010;18(3): 258-64.

12. Shrader S, Mauldin M, Hammad S, Mitcham M, Blue A. Developing a comprehensive faculty 
development program to promote interprofessional education, practice and research at a free-standing academic health science center. J Interprof Care.2015;29(2):1657.

13. rewer $M L$, Flavell $H$, Trede $F$, Smith $M$. Creating change agents for interprofessional education and practice: a leadership programme for academic staff and health practitioners. International Journal of Leadership in Education.2018;21(5):580-592.

14. Van Zanten M, Boulet JR, Greaves I. The importance of medical education accreditation standards. Med Teach.2012;34(2):136-145.

15. Barzansky B, Hunt D, Moineau G, Ahn D, Lai CW, Humphrey $\mathrm{H}$ et al. Continuous quality improvement in an accreditation system for undergraduate medical education: Benefits and challenges. Med Teach.2015;37(11):1032-1038, 2015.

16. Altmiller G, Armstrong G. National quality and safety education for nurse's faculty survey results. Nurse Educ.2017;42(5S):3-7.

17. Ard N, Beasley S, Nunn-Ellison K. Quality education through accreditation. Teaching and Learning in Nursing.2017;12(2):85-87.

18. Jaffar AA. Exploring the use of a Facebook page in anatomy education. Anat Sci Educ.2014;7(3):199-208.

19. Sterling M, Leung P, Wright D, Bishop TF. The Use of Social Media in Graduate Medical Education: A Systematic Review. Acad Med.2017;92(7): 1043-1056.

20. Latif $M Z$, Hussain I, Saeed R, Qureshi MA, Maqsood U. Use of Smart Phones and Social Media in Medical Education: Trends, Advantages, Challenges and Barriers. Acta Inform Med.2019;27(2):133.

21. Rattray J, Jones MC. Essential Elements of Questionnaire Design and Development. J Clin Nurs.2007;16:234-243.

22. Sousa VD, Rojjanasrirat W. Translation, adaptation and validation of instruments or scales for use in cross-cultural health care research: a clear and user-friendly guideline. J Eval Clin Pract.2011;17(2):268-274.

23. DeVellis RF. Scale Development: Theory and Applications (4th Ed.). Thousand Oaks, CA: Sage,2017

24. [WHO]World Health Organization. Process of translation and adaptation of instruments, 2017. [data are available at http://www. who.int/substance_abuse/research_tools/transla tion/en/]

25. Crestani $A H$, Moraes AB, Souza APR. Content validation: clarity/relevance, reliability and internal consistency of enunciative signs of language acquisition. Codas 29.2017:e20160180.

26. Jonhson B, Christensen L. Educational research: quantitative, qualitative, and mixed approaches. California, SAGE Publication, 2014. Inc.

27. Kaiser HF. A second-generation little jiffy. Psychometrika.1970;35(4):401-415, 1970.

28. Steiger $\mathrm{JH}$. Understanding the limitations of global fit assessment in structural equation modeling. Personality and Individual Differences. 2006;42(5):893-898.

29. Hooper D, Coughlan J, Mullen MR. Structural equation modelling: quidelines for determining model fit. Electronic J Business Res Methods. 2008;6(1):53-60.

30. Nunnally JC, Bernstein IH. Psychometric theory (3rd Ed.). New York, NY: McGraw-Hill, 2010. 